\section{GP188 HOSPITALISATION WITH ROTAVIRUS GASTROENTERITIS BEFORE AND AFTER ROTAVIRUS VACCINE INTRODUCTION}

Miranda Crealey*, Jennifer Hayden, Isabelle Delaney, Ethel Ryan. Galway University Hospital, Galway, Ireland

\subsection{6/archdischild-2019-epa.249}

Background Rotavirus (RV) remains one of the most common causes of acute infectious gastroenteritis (GE) worldwide. ${ }^{1}$ In developed countries, mortality due to rotavirus is low, however, the morbidity and direct healthcare costs such as laboratory tests, medications, medical care and accommodation costs associated with hospitalisations are considerably high. ${ }^{2}$ There are also the indirect economic costs such as parental work days missed. Ireland introduced Rotarix ${ }^{\circledR}$ vaccine, a monovalent, live attenuated, oral vaccination against RV into the primary Childhood Immunisation Schedule for all children born on or after $1^{\text {st }}$ October 2016.

Aim Median cost- per- episode of laboratory confirmed RV infection requiring hospitalisation in Galway University Hospital (GUH) before and after RV vaccine introduction.

Methods Data was collected retrospectively over 2 separate 1year periods (2014 and 2017) in the Paediatric department GUH, a regional hospital in west of Ireland. All Children under 5 years admitted to hospital with laboratory confirmed RVGE were included. Information regarding the length of stay, direct costs, demographic details were collected form the medical notes. Indirect costs were collected from parents over the phone.

Results There was a 57\% reduction in children admitted with RVGE in $2017(\mathrm{n}=45)$ after vaccine introduction compared with RVGE admissions in $2014(\mathrm{n}=105)$ in GUH. The median age admitted was 1.5 years (range1-4) in 2014 and 1.6 years (range $0.3-4.5$ ) in 2017. The median length of stay was unchanged; 2 nights (range 1-6) in 2014 and 2 nights (range 1-4) in 2017. The median direct cost per child per admission in 2014 was $€ 1601$ and $€ 1705$ in 2017. The total cost of RVGE admissions in GUH was reduced from $€ 160,958$ in 2014 to $€ 77,109$ in 2017 resulting in a saving of $€ 83,849$.

Conclusion There was a $57 \%$ reduction in the number of hospilisations due to RVGE in GUH in 2017- the first year after introduction of the RV vaccine in Ireland. This resulted in a direct saving of $€ 83,849$ in 2017 . This provides early evidence of the public health benefit of introducing the RV vaccine into the national immunisation programme in Ireland.

\section{REFERENCES}

1. Rotavirus burden and surveillance. Centers for Disease Control and Prevention. http://www.cdc.gov/rotavirus/surveillance.html

2. Van Damme P, Giaquinto C, Huet F, Gothefors L, Maxwell M, Van der Wielen M; REVEAL Study Group. Multicenter prospective study of the burden of rotavirus acute gastroenteritis in Europe, 2004-2005: the REVEAL study. I Infect Dis 2007 May 1;195 Suppl 1:S4-S16.

\section{GP189 PARENTAL ATTITUDES TO UNIVERSAL ANNUAL PAEDIATRIC INFLUENZA IMMUNIZATION}

${ }^{1}$ Yuxin Woon*, 1,2Edina Moylett. 'School of Medicine, NUI Galway, Galway, Ireland; ${ }^{2}$ Academic Department of Paediatrics, NUI Galway, Galway, Ireland

10.1136/archdischild-2019-epa.250

Introduction Influenza is a highly infectious, acute viral respiratory tract infection which can cause severe or even fatal complications in young children. Vaccinating healthy children would provide herd immunity against seasonal influenza which has a significant disease burden with increases in both prevalence and severity in recent years. ${ }^{1}$ As Ireland anticipates possible recommendations for universal annual paediatric influenza vaccine, it is important to identify factors that may affect vaccine uptake.

Aim To explore parental knowledge and attitudes towards influenza infection and potential factors affecting willingness to routinely vaccinate their child (ren).

Methods This descriptive study involved interviewing parents $(n=300)$ attending the paediatric outpatient department (OPD) at University Hospital Galway (UHG). UHG is a regional hospital with dedicated paediatric services. OPD clinics occur daily, morning and afternoon, general and subspecialty clinics. A pilot study assisted with standardizing the questionnaire and in optimizing the clinical catchment area (Emergency Department vs. postnatal ward vs. OPD clinics). Galway Clinical Research Ethics Committee granted the ethical approval and data was analyzed using SPSS.

Results The majority of respondents were Irish (251, 83.7\%), $236(78.7 \%)$ with private health insurance. The most frequent age range was $31-40$ years $(163,54.3 \%)$. Less than $40 \%$ had a Bachelor's degree $(113,37.7 \%)$ as their highest education level. Most participants (226, 75.3\%) agreed with annual influenza vaccine for their child if recommended.

The following factors were shown to positively affect potential annual influenza vaccine uptake, $\mathrm{p}<0.05$, $(\mathrm{N}$ and $\%$ supporting routine influenza vaccine):

Positive general perception towards childhood immunization (217, 96.1\%)

Parents who received the influenza vaccine $(127,56.2 \%)$

Mothers who received the influenza vaccine antenatally $(81$, 42.4\%)

Positive childhood immunization experiences (223, 98.7\%)

Amongst community supporting influenza vaccination $(167$, $73.9 \%)$

No concerns about influenza vaccine $(200,88.5 \%)$

High test score for parental knowledge on influenza vaccine $(33.6 \%, \mathrm{~N}=76$, achieved full marks, mean score $=4.57 \pm$ $1.28)$.

Conclusion The overall feedback for routine paediatric influenza vaccination was positive. Parental knowledge, attitudes, prior history of vaccination and social norms each had an independent influence on parents' willingness to vaccinate their child. A general lack of awareness of paediatric influenza immunization was highlighted and demonstrates the need to improve immunization awareness strategies.

\section{REFERENCES}

1. Ryan G., Cleary A., Keady D., Allen N. M., Moylett E. (2017) 2015-2016 Influenza Season in an Irish Regional Paediatric Unit: Importance of Influenza Vaccination Highlighted. Irish Medical Journal. 110(0),609.

\section{GP190 MEASLES A PREVENTABLE DISEASE THROUGH VACCINATION, BUT STILL A DEADLY MENACE IN EUROPE}

\footnotetext{
1,2Diana-Andreea Ciortea*, '2Victor Daniel Miron. ' Dr. Victor Babes' Clinical Hospital of Infectious and Tropical Disease, Bucharest, Romania; ${ }^{2}$ National Institute for Mother and Child Health 'Alessandrescu - Rusescu', Bucharest, Romania
}

10.1136/archdischild-2019-epa.251 